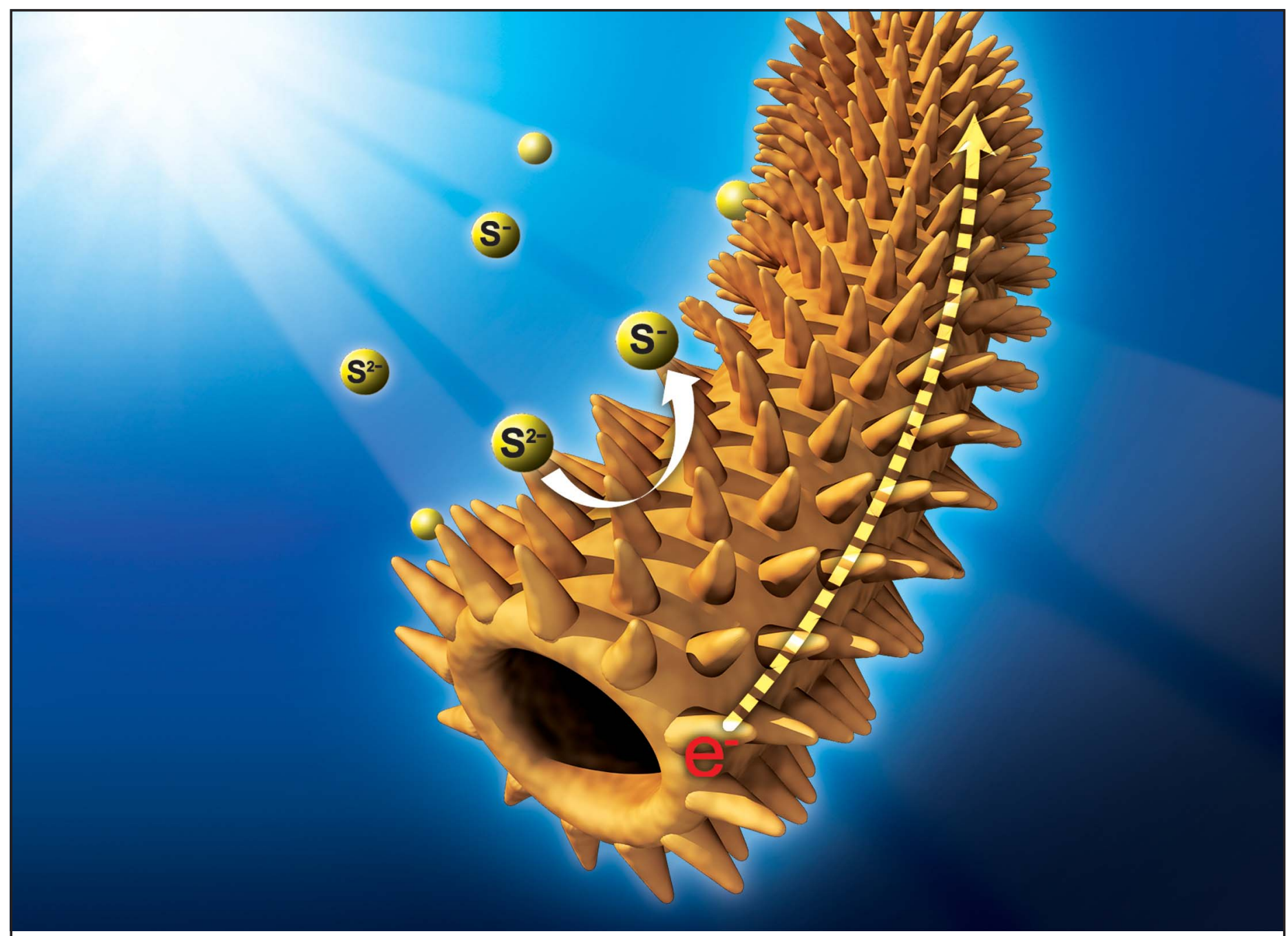

Showcasing work from a consortium of material chemists engaged in inorganic nanomaterials and photoelectrode research at Nanomaterials for Energy Conversion Laboratory (NECL) in Gwangju Institute of Science and Technology (GIST).

Title: Thorny CdSe nanotubes via an aqueous anion exchange reaction process and their photoelectrochemical applications

This work introduces a hierarchical architecture of $\mathrm{CdSe}$ nanotubes with a myriad of thorns on the surface via a simple chemical bath deposition. The thorny CdSe nanotubes are used as a photo-active electrode of a photoelectrochemical cell for generating electricity under light illumination.

\section{As featured in:}

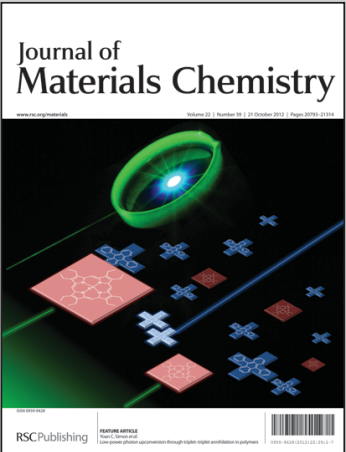

See Jeong Won Kim et al., J. Mater. Chem., 2012, 22, 20889. 


\title{
Thorny CdSe nanotubes via an aqueous anion exchange reaction process and their photoelectrochemical applications $\dagger$
}

\author{
Jeong Won Kim, ${ }^{a}$ Hee-Sang Shim, ${ }^{b}$ SungWook Ko, ${ }^{c}$ Unyoung Jeong, ${ }^{c}$ Chang-Lyoul Lee ${ }^{d}$ and Won Bae Kim*ab
}

Received 2nd May 2012, Accepted 22nd June 2012

DOI: 10.1039/c2jm32751a

In this work, a new hierarchical architecture of homogeneous CdSe thorns on CdSe nanotubes was synthesized via a simple anion exchange process from $\mathrm{Cd}(\mathrm{OH})_{2}$ nanowire bundles. The entire process for preparing the CdSe structure was performed in an aqueous chemical bath reaction in which the thorn-like branches steadily grew on the outer surface of the CdSe nanotubes. Their microstructure was analyzed by field emission scanning electron microscopy (FESEM), transmission electron microscopy (TEM), and X-ray diffraction (XRD), and their stoichiometric properties were compared using their $\mathrm{X}$-ray photoelectron spectra (XPS). The as-prepared hierarchical CdSe nanotubes showed a highly crystalline microstructure, even without thermal treatment, and the structures of the thorny grafts were controllable by a simple modification of the reaction conditions. Moreover, the photoelectrochemical properties of the chemically prepared thorny CdSe nanotubes were investigated with respect to the modified structures and their different stoichiometries.

\section{Introduction}

As one of the II-VI group semiconductors, CdSe is of great interest due to its good optical, electrical, and photoelectric properties in nanostructures. ${ }^{1,2} \mathrm{CdSe}$ is a promising candidate material for use in a wide range of applications, such as lightemitting devices, solar cells, and photodetectors. ${ }^{3-5}$ Nanometerscale morphology control at the surface of solid semiconductors could offer very sensitive photoelectrode behaviors, resulting in an improved energy conversion efficiency. Accordingly, many studies of various CdSe nanostructures have been reported. For example, the nanoparticle structures such as quantum dots obtained by chemical routes have been widely developed as a photoanode for absorbing light in photovoltaic or photoelectrochemical applications, taking advantage of tunable light absorption properties by the quantum confinement effect and efficient carrier generation by the lower photon energy threshold. ${ }^{6,7}$ However, in order that the photogenerated charge carriers can be sufficiently transported to the respective

${ }^{a}$ School of Materials Science and Engineering, Gwangju Institute of Science and Technology (GIST), Gwangju, 500-712, Republic of Korea. E-mail: wbkim@gist.ac.kr; Fax: +82 62 7152304; Tel: +82 627152317

${ }^{b}$ Research Institute for Solar and Sustainable Energies (RISE), Gwangju Institute of Science and Technology (GIST), Gwangju, Republic of Korea ${ }^{c}$ Department of Materials Science and Engineering, Yonsei University, Seoul, Republic of Korea

${ }^{d}$ Advanced Photonics Research Institute, Gwangju Institute of Science and Technology (GIST), Gwangju, Republic of Korea

$\uparrow$ Electronic supplementary information (ESI) available: Schematic diagrams, table for solution concentration, SEM image, UV-vis absorption spectra and photoelectrochemical I-V characteristics. See DOI: $10.1039 / \mathrm{c} 2 \mathrm{jm} 32751 \mathrm{a}$ electrode, the photoenergy conversion system using nanoparticles requires a continuous network which can promote a percolation of charges.

Recently, the progressive search for new heterogeneous structures has introduced advanced one dimensional (1D) nanostructures, including tetrapods, nanoneedles, nanorods, nanowires, and hollow nanostructures. ${ }^{8-12}$ The morphological characteristics of such 1D nanostructures are their extraordinary length, flexibility, and shape diversity, which enable them to be designed into various shapes using physical and chemical methods. ${ }^{13}$ With these features, functional 1D nanostructures exhibit an improved electron diffusion length by providing a direct carrier pathway which enables fast collection of photoinduced electrons. Besides, rapid charge transfer along the 1D nanostructures and efficient carrier percolation on the interface diminish charge recombination in the photoelectrode. ${ }^{12,14}$ Additionally, quantum effects can also be expected in the nanosized 1D structure. ${ }^{15}$

As more technological challenges arise, constraints on the morphological modification of inorganic 1D nanostructures have driven the research forward, requiring a larger surface area for higher activity, which can provide relatively high energy conversion efficiency. ${ }^{16}$ For versatile applications, hierarchical or hyperbranched microstructures have been proposed due to their complementary features between two structures of particles and 1D structure on the nanoscale as the structure provides a continuous network with high surface area, and they are developed through various synthetic methods. ${ }^{17}$

Although many examples of advanced 1D nanostructures have been reported, control of the sizes and shapes of the nanostructures is still difficult to achieve. For instance, the synthesis of 
nanotube structures generally requires the presence of templates or surfactants to control the sizes and shapes of the nanostructures. In our previous work, a template-free method for the synthesis of CdSe nanotubes was demonstrated using the chemical bath deposition (CBD) onto $\mathrm{Cd}(\mathrm{OH})_{2}$ nanowire bundles (NBs) that could be grown on various substrates. ${ }^{18,19}$ The dimensions of the CdSe nanotubes were readily controllable as a function of the size of the sacrificial substances, even without employing artificial surfactants or templates.

In this paper, we further illustrate the simple preparation and characterization of hierarchical $\mathrm{CdSe}$ nanostructures on nanotubes, producing thorny $\mathrm{CdSe}$ nanotubes with an equivalent chemical composition. The thorny CdSe nanotubes can be easily fabricated over relatively large surface areas, and their size is also effectively controlled with their chemical characteristics, such as their stoichiometry. Among the reported inorganic nanostructures, a nanotube structure with multiple thorns protruding from the main branch of each nanotube is a unique morphology. Thorny CdSe nanotubes have been used in photoelectrochemical cell applications to investigate their photoelectrochemical properties and dependence of those properties on the variation in the size and stoichiometry of the thorny CdSe nanotubes.

\section{Experimental}

\section{Synthesis of $\mathrm{Cd}(\mathrm{OH})_{2}$ nanowire bundles}

For the preparation of $\mathrm{Cd}(\mathrm{OH})_{2} \mathrm{NBs}, 3.08 \mathrm{~g}(0.1 \mathrm{~mol})$ of cadmium nitrate tetrahydrate $\left(\mathrm{Cd}\left(\mathrm{NO}_{3}\right)_{2} \cdot 4 \mathrm{H}_{2} \mathrm{O}, 98 \%\right.$, Aldrich) was dissolved in $100 \mathrm{ml}$ of deionized (DI) water. Then, ammonium hydroxide $\left(\mathrm{NH}_{4} \mathrm{OH}, 28 \%\right.$, Aldrich) was added to the solution, and the solution was stirred on a magnetic plate for a few minutes. A white precipitate was initially observed. Upon further addition of the $\mathrm{NH}_{4} \mathrm{OH}$, the white precipitate dissolved, and the solution became clear at a $\mathrm{pH}$ of approximately $11 .{ }^{18}$ Several pre-cleaned glass substrates and silicon wafers were immersed and suspended vertically in the solution using a holder. The solution was maintained at $60{ }^{\circ} \mathrm{C}$ for $5 \mathrm{~h}$ in a bath, resulting in direct growth of the $\mathrm{Cd}(\mathrm{OH})_{2}$ nanowire bundles onto the glass substrates. The substrates were subsequently removed from the aqueous alkaline solution and washed with DI water. The washed substrates were dried sufficiently under air and prepared as a sacrificial template.

\section{Conversion into thorny CdSe nanotubes}

In a typical synthesis, an aqueous solution of NaHSe as a selenium precursor was prepared by refluxing the solution at $70{ }^{\circ} \mathrm{C}$ for $30 \mathrm{~min}$. The NaHSe solution was prepared by dissolving 10 $\mathrm{mM}$ of selenium (Se powder, $99.5 \%$, Aldrich) as a Se ion source in $10 \mathrm{mM}$ sodium borohydride solution $\left(\mathrm{NaBH}_{4}, 98.5 \%\right.$, Aldrich) as a reducing agent. The $\mathrm{NaBH}_{4}$ served as an alkaline agent in the aqueous solution, providing more favorable conditions that promoted $\mathrm{Se}^{2-}$ formation. ${ }^{20}$

Next, $\mathrm{Cd}(\mathrm{OH})_{2} \mathrm{NBs}$ on the substrates were immersed into the prepared $\mathrm{NaHSe}$ solution for several minutes. The $\mathrm{Cd}(\mathrm{OH})_{2} \mathrm{NBs}$ acted as sacrificial templates for chemical transformation. After the chemical reaction was completed by exchanging anions between the $\mathrm{OH}^{-}$ion in the $\mathrm{Cd}(\mathrm{OH})_{2} \mathrm{NBs}$ and the $\mathrm{Se}^{2-}$ ion in the $\mathrm{NaHSe}$ solution, the substrates were taken out of the solution and rinsed with DI water. To eliminate impurities such as residual Se and prevent any ligand adsorptions on the surface, the synthesized thorny CdSe nanotubes were soaked in trioctylphosphine (TOP) for $1 \mathrm{~min}$ at room temperature. After the purifying process, the successfully obtained CdSe nanostructures were dried sufficiently at $70{ }^{\circ} \mathrm{C}$ under air.

\section{Characterization techniques}

X-ray diffraction (XRD) measurements were performed with a Rigaku Rotalflex (Ru-200B) X-ray diffractometer using CuK $\alpha$ radiation $(\lambda=1.5405 \AA)$ with a Ni filter. The source was operated at $40 \mathrm{kV}$ and $100 \mathrm{~mA}$. The 2 theta angular region between $20^{\circ}$ and $60^{\circ}$ was explored in a fixed time mode $\left(0.02^{\circ}\right.$ per $\left.\mathrm{s}\right)$.

The shapes and morphologies of the thorny CdSe nanotubes were investigated by field-emission scanning electron microscopy (FESEM, Hitachi S-4700) and transmission electron microscopy (TEM, TECNAI F20). All TEM samples were prepared by ultrasonically dispersing the hierarchical CdSe nanotubes in a mixed solution containing ethanol and DI water. A drop of the dispersed solution was deposited onto a standard $\mathrm{Cu}$ grid (200mesh) covered with a carbon film and dried for $4 \mathrm{~h}$ in a convection oven to allow the solvent to evaporate, leaving the hierarchical $\mathrm{CdSe}$ nanotube structures dispersed on the $\mathrm{Cu}$ grid.

To analyze the chemical state and stoichiometry of the thorny CdSe nanotubes, X-ray photoelectron spectroscopy (XPS, ESCALAB 250, UK) was employed using a monochromic Al K $\alpha$ $\mathrm{X}$-ray source $(E=1486.6 \mathrm{eV})$. Data processing was performed using the XPSPEAK software program. The background was corrected using the Shirley method, and the binding energy of the $\mathrm{C} 1 \mathrm{~s}$ peak from the support at $285.18 \mathrm{eV}$ was taken as an internal standard.

Furthermore, measurements of the optoelectronic properties of the thorny CdSe nanotube electrodes were obtained by UV-vis absorption spectroscopy (Lamda 750 UV/VIS Spectrometer) and $I-V$ measurements under dark conditions, as well as under 100 $\mathrm{mW} \mathrm{cm} \mathrm{cm}^{-2}$ light produced by a $500 \mathrm{~W}$ Xenon lamp equipped with an AM $1.5 \mathrm{G}$ filter.

For the electrochemical analysis, the thorny CdSe nanotubes were directly synthesized on indium tin oxide (ITO) glass and used as a working electrode at the photoelectrochemical cell in which a conventional three-electrode configuration was employed (Scheme S1 in ESI $\dagger$ ), with a thin Pt wire as the counter electrode and a $\mathrm{Ag} / \mathrm{AgCl}$ electrode as a reference electrode in $1 \mathrm{M}$ polysulfide aqueous electrolyte consisting of $\mathrm{NaOH}, \mathrm{Na}_{2} \mathrm{~S}$, and $\mathrm{S}$ (each $1 \mathrm{M}) .^{21}$

\section{Results and discussion}

Fig. 1 shows the morphology and phase identification of the synthesized nanostructures. The $\mathrm{Cd}(\mathrm{OH})_{2} \mathrm{NBs}$ used as sacrificial templates for the hierarchical $\mathrm{CdSe}$ nanostructures were prepared by $\mathrm{CBD}$, in which the size of the $\mathrm{Cd}(\mathrm{OH})_{2} \mathrm{NBs}$ could be easily tuned by controlling the formation time. ${ }^{18}$ The diameter of the synthesized $\mathrm{Cd}(\mathrm{OH})_{2} \mathrm{NBs}$ was restricted to $60 \mathrm{~nm}$ in this work (Fig. 1a). The $\mathrm{Cd}(\mathrm{OH})_{2} \mathrm{NBs}$ with $60 \mathrm{~nm}$ diameter were converted completely to $\mathrm{CdSe}$ nanostructures by an anion exchange reaction between $\mathrm{Cd}(\mathrm{OH})_{2}$ and $\mathrm{Se}^{2-}$ in an aqueous solution of $\mathrm{NaHSe}$, which was maintained at $70{ }^{\circ} \mathrm{C}$. Fig. $1 \mathrm{~b}-\mathrm{d}$ 


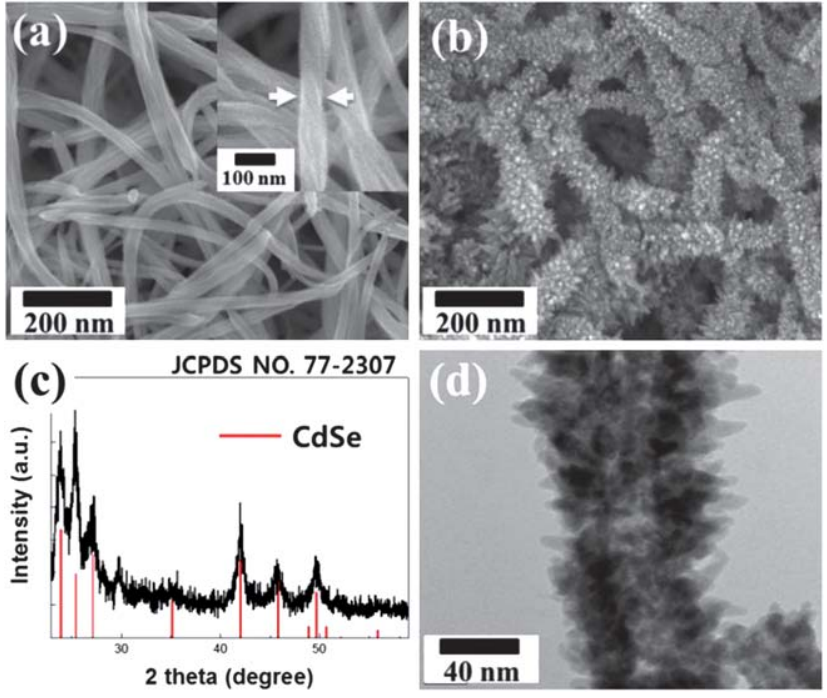

Fig. 1 FESEM images of (a) $\mathrm{Cd}(\mathrm{OH})_{2}$ nanowire bundles as the sacrificial template and (b) thorny CdSe nanotubes. (c) XRD pattern and (d) TEM image of the thorny CdSe nanotubes.

reveal the microstructure and crystallinity of the nanostructures converted from the $\mathrm{Cd}(\mathrm{OH})_{2}$ NBs. The surface morphology of the converted $\mathrm{CdSe}$ nanostructures appears to be very rough (Fig. 1b), as a myriad of thorns were homogeneously formed on the surfaces of the CdSe nanostructures. The crystal phase identification of the synthesized nanostructures was performed by XRD measurement, in which the diffraction peaks were unambiguously indexed to the hexagonal wurtzite structure of CdSe. This result corresponds to the reference on JCPDS card no. 77-2307, with lattice parameters of $a=0.430 \mathrm{~nm}$ and $c=$ $0.701 \mathrm{~nm}$ from Fig. 1c. The TEM image shown in Fig. 1d illustrates that the nanostructures formed thorn-like branches on the outer wall of the hollow nanotube. As a whole, Fig. 1 shows templates via an anion exchange reaction in an aqueous solution.
The reaction parameters that played a significant role in transforming $\mathrm{Cd}(\mathrm{OH})_{2}$ NBs into hierarchical-structured $\mathrm{CdSe}$ nanotubes were the reaction time, precursor concentration, amount of reducing agent, and bath temperature. Among these parameters, the reaction time directly affected the density and length of the CdSe thorns that formed on the CdSe nanotube. Fig. 2a-d explain how these factors change the surfaces of the CdSe nanotubes. Fig. 2e-h show the TEM images, which clearly depict the hierarchical CdSe tubular nanostructures according to the reaction time. Fig. 2a and e show SEM and TEM images, respectively, of the initial state of the chemical reaction in the aqueous NaHSe solution. After the chemical reaction proceeded in the aqueous solution for $30 \mathrm{~s}$, small particles were observed on the surfaces of the nanotubes in the SEM image. However, the TEM image (Fig. 2e) shows that the tiny thorns grew vertically from the outer shell of the sacrificial template. In addition, the formation of the tubular structure appears to have occurred in a very short time (as displayed in the inset in Fig. 2a) because the anion exchange reaction of $\mathrm{Cd}(\mathrm{OH})_{2}$ is rapid, along with the outward diffusion of $\mathrm{Cd}^{2+}$ in the NaHSe aqueous solution. ${ }^{19,22}$ As the reaction proceeded, the tubular structures became more defined, and the thorns also grew (Fig. 2e-h). The length of thorns that protruded from the nanotube surface was approximately $\sim 40 \mathrm{~nm}$, as shown in Fig. $2 \mathrm{~h}$. This value is nearly half of the diameter of the initially formed nanotube. These relatively long thorns were able to grow until the $\mathrm{Cd}$ source was no longer provided by the inner $\mathrm{Cd}(\mathrm{OH})_{2}$ NBs. Fig. 3 depicts the XRD patterns taken from each intermediate phase of the as-synthesized thorny CdSe nanotubes. The XRD pattern indicates that an amorphous microstructure was present after $30 \mathrm{~s}$ of reaction, but the persistent microstructure after a minute is classified as a hexagonal wurtzite structure of $\mathrm{CdSe}$, in comparison with Fig. 1c. It means that the transformation of the sacrificial $\mathrm{Cd}(\mathrm{OH})_{2}$ template into CdSe through the anion exchange reaction occurred within 1 minute. The XRD peaks generally sharpened as the reaction time increased. Interestingly, the peak
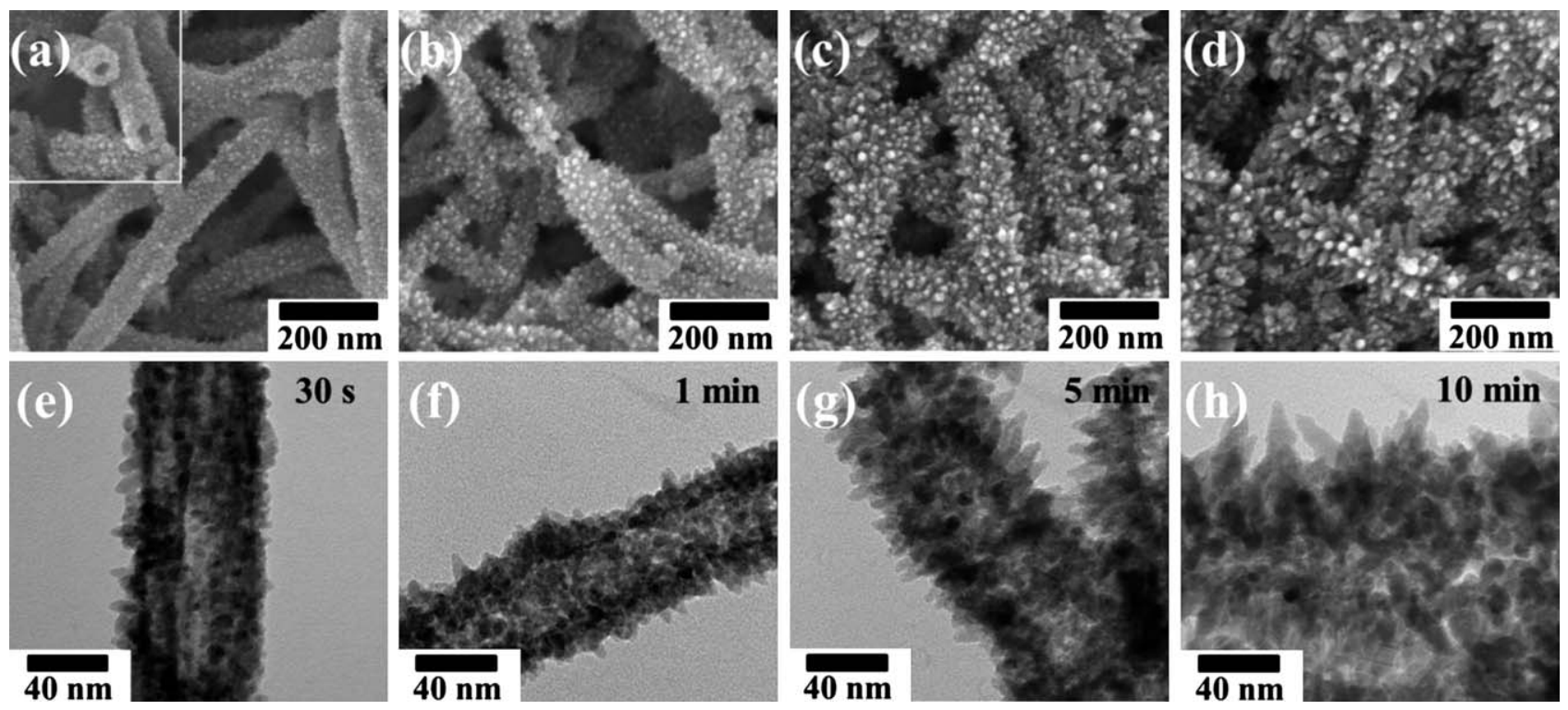

Fig. 2 FESEM images of the samples converted for (a) $30 \mathrm{~s}$, (b) $1 \mathrm{~min}$, (c) $5 \mathrm{~min}$, and (d) $10 \mathrm{~min}$ in the NaHSe aqueous solution. TEM images of thorny CdSe nanotubes obtained after (e) $30 \mathrm{~s}$, (f) $1 \mathrm{~min}$, (g) $5 \mathrm{~min}$, and (h) $10 \mathrm{~min}$ in the solution. 


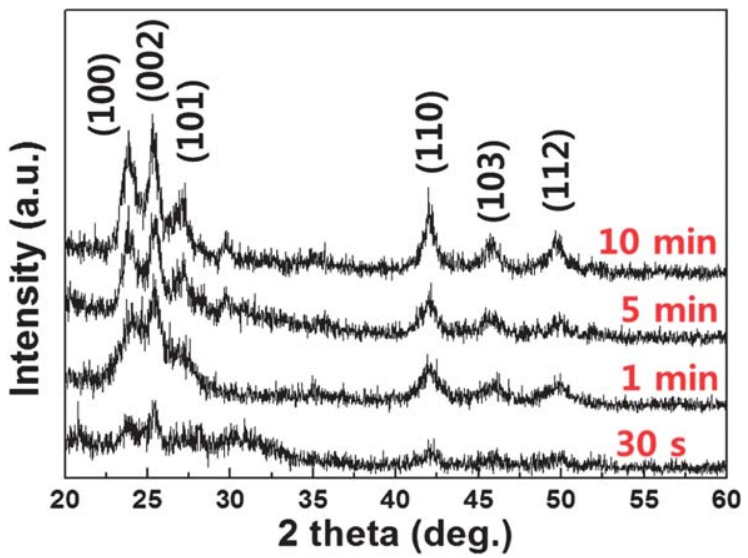

Fig. 3 The XRD diffraction patterns of thorny CdSe nanotubes synthesized for $30 \mathrm{~s}$, and 1, 5, and $10 \mathrm{~min}$ in an aqueous solution.

at (002) showed the highest intensity among all of the XRD peaks.

The TEM image in Fig. 4a illustrates the anisotropic growth of thorns from the surface of the nanotubes following the tubular formation of CdSe. Fig. 4a illustrates that all of the thorn-like branches grew on the outer shell of the nanotube surface and spread out radially with the nanotube as the center axis. High resolution TEM (HRTEM) was used to investigate their structure. The TEM images show that the thorns had a single crystalline phase, as shown in Fig. 4b. The inter-planar spacing in the inset of Fig. $3 b$ was measured to be approximately $0.35 \mathrm{~nm}$, which is in agreement with the (002) crystalline plane of hexagonal CdSe. This spacing may be the reason that the (002) phase in the XRD patterns of Fig. 3 appears to be comparatively higher in intensity than that of the reference peak. These distinct features of heterostructured thorny nanotubes possessing a single crystalline phase suggest a wide range of applications that require good electron affinity and a large surface area.

The XPS analysis provided additional information for characterizing the stoichiometry of the product. Systematic XPS analysis was carried out on the initial, intermediate, and final phases of the thorny $\mathrm{CdSe}$ according to the chemical reaction time. The resulting narrow XPS spectra assigned to $\mathrm{Cd} 3 \mathrm{~d}$ and $\mathrm{Se}$ $3 \mathrm{~d}$ for each stage are shown in Fig. 5. The Cd 3d XPS spectra collected in the initial phase $(1 \mathrm{~min})$ consist of two peaks, corresponding to $\mathrm{Cd} 3 \mathrm{~d}_{5 / 2}$ and $\mathrm{Cd} 3 \mathrm{~d}_{3 / 2}$ states from the spin-orbital splitting. To identify the synthesized product, each peak of the bound $\mathrm{Cd}$ state was deconvoluted into two different $\mathrm{Cd}$
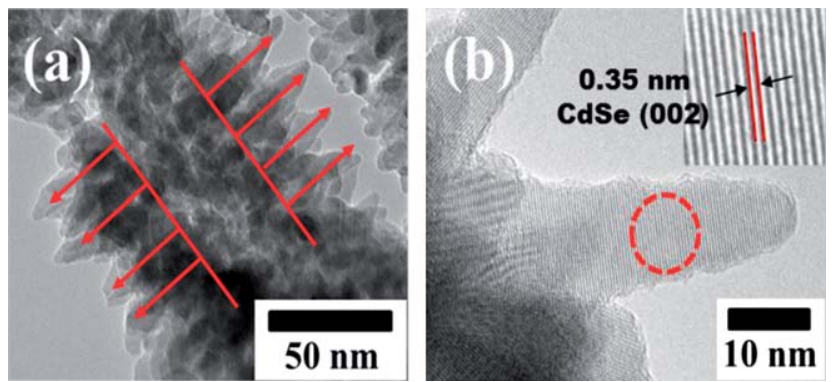

Fig. 4 (a) TEM and (b) HRTEM images of thorny CdSe nanotubes. compound states: $\mathrm{CdSe}$ and $\mathrm{Cd}(\mathrm{OH})_{2}$. The deconvoluted $\mathrm{Cd} 3 \mathrm{~d}$ peaks near binding energies of $411.4 \mathrm{eV}\left(\mathrm{Cd} \mathrm{3d}_{3 / 2} \mathrm{a}\right)$ and $404.8 \mathrm{eV}$ $\left(\mathrm{Cd} 3 \mathrm{~d}_{5 / 2}\right.$ a) correspond to the Cd state in CdSe, and additional

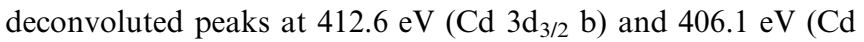
$3 \mathrm{~d}_{5 / 2}$ b) demonstrate the $\mathrm{Cd}$ state bound with $2(\mathrm{OH})^{-}$, like $\mathrm{Cd}(\mathrm{OH})_{2} \cdot{ }^{21}$ These decoupled components at the $\mathrm{Cd} 3 \mathrm{~d}$ doublet demonstrate that the initial phase of the early chemical reaction was a composite phase that consisted of $\mathrm{Cd}(\mathrm{OH})_{2}$ and $\mathrm{CdSe}$. Furthermore, the fractions of the two $\mathrm{Cd}$ species that were estimated from the relative areas of their deconvoluted peaks, in which the $\mathrm{Cd}$ state of $\mathrm{CdSe}$ is predominant, also indicate that $\mathrm{Cd}(\mathrm{OH})_{2}$ transformed almost to the CdSe phase after $1 \mathrm{~min}$ reaction time.

In the cases of products obtained after $5 \mathrm{~min}$ and $10 \mathrm{~min}$, the $\mathrm{Cd} 3 \mathrm{~d}$ peaks were also divided into two components, corresponding to $3 \mathrm{~d}_{5 / 2}$ and $3 \mathrm{~d}_{3 / 2}$, as summarized in Table 1 . The $\mathrm{Cd} 3 \mathrm{~d}$ doublet and its separation of approximately $6.7 \mathrm{eV}$ clearly indicate the existence of $\mathrm{Cd}$ species from CdSe. ${ }^{23}$ In Fig. 5 (right), the position of the Se $3 \mathrm{~d}$ binding energy appears near $54 \mathrm{eV}$, and the deconvolution of each peak shows the presence of two decoupled components between 53 and $55 \mathrm{eV}$ because of the $3 \mathrm{~d}_{5 / 2}$ and $3 \mathrm{~d}_{3 / 2}$ spins, which also occurred from CdSe. ${ }^{13 a, 23}$ There were no extra decoupled components in the fitted curve, allowing us to exclude the possibility that impurities such as unreacted Se or oxidized $\mathrm{SeO}_{2}$ were present. With the increased reaction time, the stoichiometry between $\mathrm{Cd}$ and Se changed, as shown in Table 1, and the atomic ratio of $\mathrm{Cd}$ : Se was maintained at the same chemical ratio, even for a prolonged reaction time. Even if a large quantity of $\mathrm{Se}^{2-}$ ions existed in the aqueous NaHSe solution, there was no additional reaction with a chemical ratio greater than $1: 1$ between $\mathrm{Cd}$ and $\mathrm{Se}$. It is noteworthy that the initial amount of $\mathrm{Cd}$ in the sacrificial $\mathrm{Cd}(\mathrm{OH})_{2}$ template could determine the final composition of $\mathrm{Se}$ in the thorny $\mathrm{CdSe}$ nanotubes. With an increase in the Se fraction of the fabricated nanostructure, the Se $3 \mathrm{~d}$ XPS peak was likely shifted to higher binding energies, along with a significant increase in the peak intensity proportional to the amount of selenium that was converted instead of hydroxide, as observed in Fig. 5 (right).

Scheme 1 shows the sequential process for the synthesis of thorny CdSe nanotubes from the $\mathrm{Cd}(\mathrm{OH})_{2} \mathrm{NBs}$. Scheme 1a

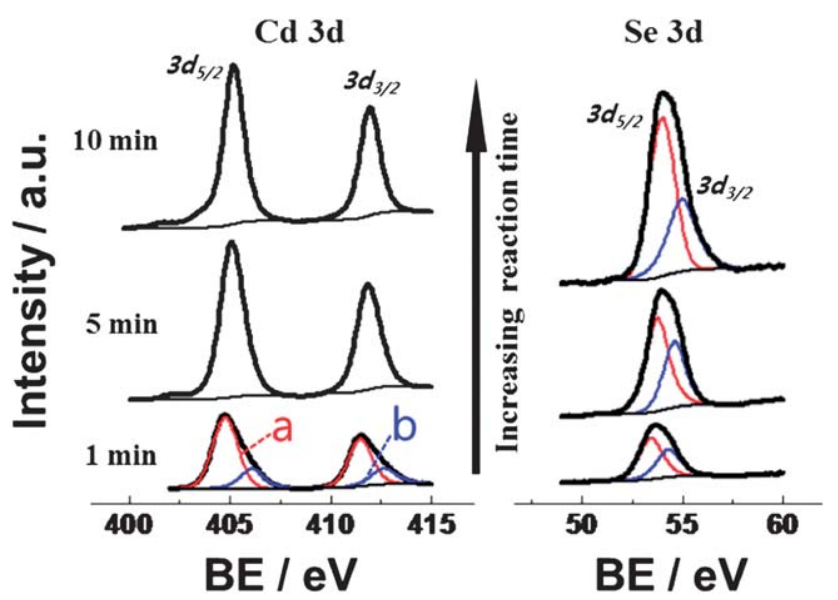

Fig. 5 XPS spectra for Cd $3 d$ and Se $3 d$ of thorny CdSe nanotubes formed by 1,5 , and $10 \mathrm{~min}$ reaction time. 
Table 1 Electronic parameters of the thorny CdSe nanotubes characterized by XPS

\begin{tabular}{|c|c|c|c|c|c|c|c|}
\hline \multirow{2}{*}{$\begin{array}{l}\text { Reaction } \\
\text { time }\end{array}$} & \multicolumn{5}{|c|}{ Binding energy $(\mathrm{eV})$} & \multicolumn{2}{|c|}{$\begin{array}{l}\text { Atomic } \\
\text { ratio }^{c}\end{array}$} \\
\hline & $\mathrm{Cd} 3 \mathrm{~d}_{5 / 2}$ & $\mathrm{Cd} 3 \mathrm{~d}_{3 / 2}$ & Se $3 d$ & Se $3 d_{5 / 2}$ & Se $3 d_{3 / 2}$ & $\mathrm{Cd}$ & $\mathrm{Se}$ \\
\hline $1 \mathrm{~min}$ & $\begin{array}{l}404.8^{a} \\
406.1^{b}\end{array}$ & $\begin{array}{l}411.4^{a} \\
412.6^{b}\end{array}$ & 54.2 & 53.4 & 54.3 & 1 & 0.5 \\
\hline $5 \mathrm{~min}$ & 405.1 & 411.8 & 54.0 & 53.8 & 54.6 & 1 & 0.7 \\
\hline $10 \mathrm{~min}$ & 405.2 & 411.9 & 53.7 & 54.0 & 55.0 & 1 & 1.0 \\
\hline
\end{tabular}

${ }^{a}$ Binding energy of $\mathrm{Cd}$ combined with $\mathrm{Se}^{2-} \cdot{ }^{b}$ Binding energy of $\mathrm{Cd}$ combined with $2(\mathrm{OH})^{-}$. ${ }^{c}$ Surface $\mathrm{Cd}:$ Se atomic ratio calculated from XPS by using peak areas normalized on the basis of sensitivity factor.

represents the $\mathrm{Cd}(\mathrm{OH})_{2} \mathrm{NB}$ template grown on a substrate by controlled chemical precipitation and nucleation, as explained in ref. 18. The prepared $\mathrm{Cd}(\mathrm{OH})_{2}$ template is composed of individual smaller nanowires which range from 7 to $10 \mathrm{~nm}$ in diameter. In a NaHSe aqueous solution, $\mathrm{Se}^{2-}$ ions substitute for $(\mathrm{OH})_{2}$ on the sacrificial template via an anion exchange reaction, and the displaced $\mathrm{OH}^{-}$ions are dissolved into the aqueous solution of the chemical bath. Then, an outer shell of CdSe begins to form on the surface of the $\mathrm{Cd}(\mathrm{OH})_{2} \mathrm{NBs}$ through the inward diffusion of $\mathrm{Se}^{2-}$ and outward diffusion of $\mathrm{Cd}^{2+}$ via the Kirkendall diffusion process which leads to void or vacancy formation inside the interface (Scheme 1b). ${ }^{24}$ The chemical potential difference between the inner and outer phases produced by the outer shell of CdSe causes the Kirkendall diffusion effects and helps to maintain the diffusion process as a driving force until the reaction is complete. The interdiffusion of $\mathrm{Se}^{2-}$ and $\mathrm{Cd}^{2+}$ occurs through the CdSe outer shell as illustrated in Scheme $\mathrm{S} 2$ of ESI $\dagger$ as the growth mechanism is dominantly influenced by the curvature and surface energetics on the nanoscale. ${ }^{25}$ As a result, the vacancies clearly accumulate in the inner space as well as the formed CdSe shell becomes thicker. Herein, the bundled structure of the sacrificial template may have provided a more efficient inter-diffusion pathway than a thick nanowire for the delivery of the $\mathrm{Se}^{2-}$ in the solution phase and the $\mathrm{Cd}^{2+}$ in the solid phase. ${ }^{26}$ Upon completion of this diffusion process across the hollow structure, the CdSe nanotubes can be generated within $1 \mathrm{~min}$. Simultaneously, a core-shell structure of $\mathrm{Cd}(\mathrm{OH})_{2} /$
CdSe with small protruding thorns on the surface is formed, as shown in Scheme 1c, which would correspond to the early phase of Fig. 2e.

Many thorns were created and grown on the surface of the fabricated CdSe nanotubes. The principal factor for the dimensional control of the thorn-like branches is the concentration of $\mathrm{Se}^{2-}$ in the NaHSe aqueous solution (see Table $\mathrm{S} 1$ of the ESI $\dagger$ ). Depending on the concentration of $\mathrm{Se}^{2-}$ in the NaHSe solution, as shown in Table $\mathrm{S} 1, \dagger$ the morphology of CdSe nanotubes could be restricted to a thorny CdSe nanotube with a rough surface or a CdSe nanotube with a smooth surface, as shown in Fig. S1. $\dagger$ At low Se precursor concentrations (italic type in Table S1†), the surface of the synthesized nanotube was covered with multiple large thorns (Fig. S1a $\dagger$ ). Conversely, in the case of a relatively high concentration of the Se precursor, the synthesized CdSe nanotubes had a clean and smooth surface (Fig. S2b $\dagger$ ). This distinct surface morphology can be explained by the difference in nuclei formation with varying precursor concentrations because the concentration of precursor in the solution affected the stable chemical reaction and the diffusion rate of the reactant. ${ }^{27}$ The ratio of reactive $\mathrm{Se}$ ions to $\mathrm{Cd}$ ions $\left(\mathrm{Se}^{2-} / \mathrm{Cd}^{2+}\right)$ on the surface is relatively high at high Se concentrations, which leads to a uniform chemical reaction with stable ion exchange, so that the surface of the fabricated CdSe nanotube is smooth, without any thorn growth. In contrast, at low Se concentrations, the ratio of reactive $\mathrm{Se}$ ions to $\mathrm{Cd}$ ions $\left(\mathrm{Se}^{2+} / \mathrm{Cd}^{2-}\right)$ on the surface is relatively low, and it promotes unstable surface reactions and more active diffusion of the $\mathrm{Cd}^{2+}$ ions. This process causes local site selectivity for the CdSe seeds to develop on the surface. Then, the $\mathrm{CdSe}$ seeds on the surface affect the more active outward-diffusion of the cation ions, and they produce anisotropic and radial branches which grow along the (002) crystal plane on the surface (Fig. 4).

Consequently, through the anion exchange reaction and Kirkendall effect, a facile solution-based phase transfer using CBD facilitates selenization on the $\mathrm{Cd}(\mathrm{OH})_{2}$ sacrificial template within a very short time, as shown in Fig. 2 and 5. Furthermore, the small thorn-like branches, which were created by the unstable surface reaction, grow gradually with outward diffusion of the $\mathrm{Cd}^{2+}$ ions, and when all of the $\mathrm{Cd}$ sources in the sacrificial template are consumed, the growth of the thorns is also terminated. At this point, Scheme 1d shows a thorny CdSe nanotube

\section{- Se ion $\square \mathrm{Cd}(\mathrm{OH})_{2} \square \mathrm{CdSe}$}

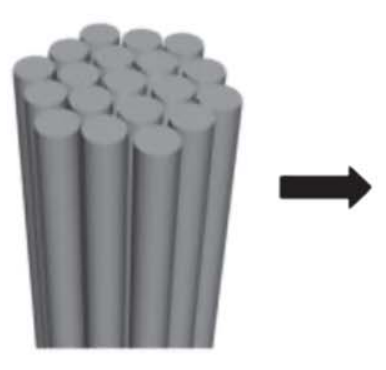

(a)

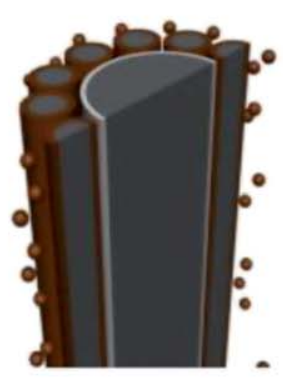

(b)
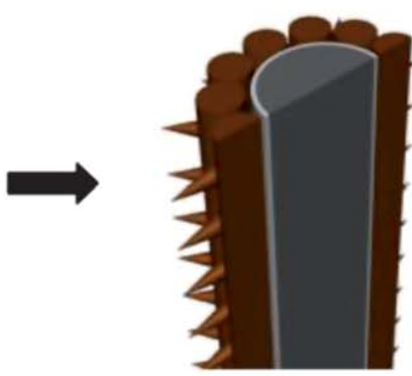

(c)

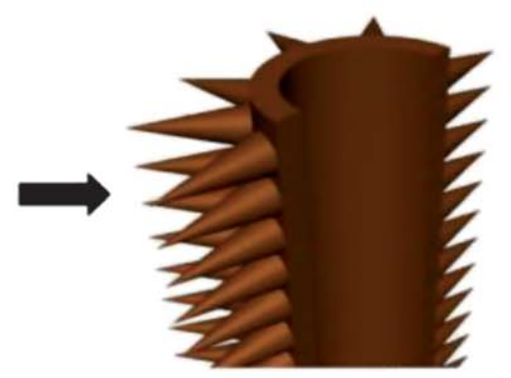

(d)

Scheme 1 Illustration of the formation of thorny CdSe nanotubes from $\mathrm{Cd}(\mathrm{OH})_{2}$ nanobundles. 
that was fully converted from the $\mathrm{Cd}(\mathrm{OH})_{2}$ template after $7 \mathrm{~min}$ of chemical reaction.

For investigation of the photoelectrochemical properties of the thorny CdSe nanotubes, CdSe electrodes with various phases of thorny CdSe nanotubes were compared as photoanodes in a photoelectrochemical system (ITO/thorny CdSe NTs/polysulfide electrolyte/Pt) using a three-electrode configuration under dark and light illumination conditions. We have attempted to distinguish PEC current-voltage properties as they depend on the atomic ratios of the thorny CdSe nanotubes. Fig. 6 clearly shows the photocurrent density curve versus the applied voltage as it relates to the atomic ratio and the photovoltaic parameters of the PEC cell that are reported in Table 2. The samples from 1 and 5 min reaction time represent thorny $\mathrm{CdSe}$ nanotubes that possess atomic ratios of $1: 0.5$ and $1: 0.7$, respectively, and the nanotubes prepared with 7 and 10 min reaction time are thorny $\mathrm{CdSe}$ nanotubes that have a well-balanced $\mathrm{Cd}: \mathrm{Se}$ stoichiometry of $1: 1$. As the atomic ratio of $\mathrm{Cd}: \mathrm{Se}$ in the thorny CdSe nanotubes approaches $1: 1$, the photocurrent density $\left(J_{\mathrm{sc}}\right)$ and photoconversion efficiency $(\eta)$, as summarized in Table 2 , are significantly enhanced, reaching $13.15 \mathrm{~mA} \mathrm{~cm}^{-2}$ and $2.12 \%$, respectively. Although the stoichiometry of each phase is different, the onset potentials $\left(V_{\mathrm{oc}}\right)$ of the samples are approximately $0.75 \mathrm{~V}$ (vs. $\mathrm{Ag} / \mathrm{AgCl}$ ). This result illustrates that the synthesized nanostructures have similar energy band gaps, in agreement with the light absorbance in Fig. S2, $\dagger$ indicating that the absorption of all samples occurs at approximately $720 \mathrm{~nm}$. Interestingly, the nanostructures with atomic ratios of $1: 0.7$ and $1: 1(\mathrm{Cd}: \mathrm{Se})$ exhibited similar light absorption behavior (see Fig. S2 of the ESI $\dagger$ ). However, the PEC data in Fig. 6 show different performances for the samples with atomic ratios of $1: 0.7$ and $1: 1$. These data indicate that well-balanced CdSe provides effective carrier transport because the photoelectrode with $1: 1$ stoichiometry more efficiently generates the photo-induced current density and provides better PEC cell performance, despite having similar light absorption to the CdSe with disproportionate $\mathrm{Cd}$ : Se stoichiometric ratios.

For the electrochemical comparison between thorny nanotubes and simple nanotubes, another comparative PEC analysis was evaluated as shown in Fig. S3 of the ESI. $\dagger$ As a result, the

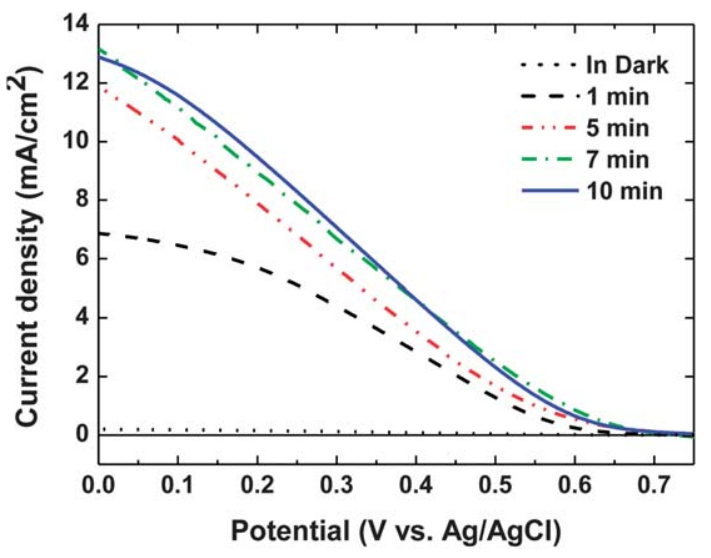

Fig. $6 I-V$ characteristics of photoelectrochemical solar cells using a photoanode comprised of thorny CdSe nanotubes that were synthesized at various reaction times.
Table 2 Parameters estimated from the PEC performances of thorny CdSe nanotubes

\begin{tabular}{lllll}
\hline $\begin{array}{l}\text { Reaction } \\
\text { time }\end{array}$ & $V_{\mathrm{oc}}(\mathrm{V})$ & $J_{\mathrm{sc}}\left(\mathrm{mA} \mathrm{cm}^{-2}\right)$ & $\mathrm{FF}$ & $\eta(\%)$ \\
\hline $1 \mathrm{~min}$ & 0.73 & 6.86 & 0.26 & 1.32 \\
$5 \mathrm{~min}$ & 0.77 & 11.87 & 0.19 & 1.72 \\
$7 \mathrm{~min}$ & 0.72 & 13.15 & 0.21 & 2.02 \\
$10 \mathrm{~min}$ & 0.79 & 12.89 & 0.21 & 2.12 \\
\hline
\end{tabular}

short circuit current density and efficiency of thorny nanotubes were enhanced from 10 to $12 \mathrm{~mA} \mathrm{~cm}^{-2}$ and 1.88 to $2.05 \%$, respectively, as compared to the simple nanotube.

Further optimization and investigation will reveal promising applications of the thorny CdSe nanotubes as photoanodes for photoconversion devices.

\section{Conclusions}

In a basic solution, the hydroxide species in $\mathrm{Cd}(\mathrm{OH})_{2}$ is readily ionized into the solution, and the vacancy is replaced by a $\mathrm{Se}^{2-}$ ion in an aqueous solution. Subsequently, thorny CdSe nanotubes are synthesized via a simple anion exchange process from the sacrificial $\mathrm{Cd}(\mathrm{OH})_{2}$ template, and the unstable nuclei on the $\mathrm{CdSe}$ nanotube surface leads to the formation of radial $\mathrm{CdSe}$ thorns that are protruded from the central nanotube and possess a single crystalline microstructure. When employed the thorny CdSe nanotubes as a photoanode in a PEC cell, the photocurrent efficiency was approximately $2.1 \%$ under $100 \mathrm{~mW} \mathrm{~cm}^{-2}$ illumination, and the photoelectrochemical performance was dependent on the CdSe stoichiometry. The thorny CdSe nanotubes fabricated here by a facile method that generated a hierarchical 1D nanostructure may be used in a wide range of electronic and optoelectronic applications in which a nanoscale microstructure is required for higher activity.

\section{Acknowledgements}

This work was supported by the Global Frontier R\&D Program on Center for Multiscale Energy System funded by the National Research Foundation under the Ministry of Education, Science and Technology, Korea (no. 0420-20110157) and the National Research Foundation of Korea (NRF) grant funded by the Korea government (MEST) (no. 20110016600) (Mid-career Researcher Program).

\section{Notes and references}

1 Z. L. Wang, Adv. Mater., 2003, 15, 432.

2 V. V. Kislyuk and O. P. Dimitriev, J. Nanosci. Nanotechnol., 2008, 8, 131.

3 S. Coe, W.-K. Woo, M. Bawendi and V. Bulović, Nature, 2002, 420, 800.

4 (a) W. U. Huynh, J. J. Dittmer and A. P. Alivisatos, Science, 2002, 295, 2425; (b) B. Sun, E. Marx and N. C. Greenham, Nano Lett., 2003, 3, 961 .

5 C. F. Hermandez, D. J. Suh, B. Kippelen and S. R. Marder, Appl. Phys. Lett., 2004, 85, 534.

6 (a) C. B. Murray, D. J. Norris and M. G. Bawendi, J. Am. Chem. Soc., 1993, 115, 8706; (b) J. A. Peng and X. Peng, J. Am. Chem. Soc., 2001, 123, 183; (c) S. Yochelis and G. Hodes, Chem. Mater., 2004, 16, 2740; 
(d) D. Pan, Q. Wang, S. Jiang, X. Ji and L. An, J. Phys. Chem. C, 2007, 111, 5661.

7 (a) D. J. Millerson, I. Gur and A. P. Alivisatos, MRS Bull., 2005, 30, 41; (b) A. J. Nozik, Chem. Phys. Lett., 2008, 457, 3; (c) T.-W. F. Chang, S. Musikihin, L. Bakueva, L. Levina, M. A. Hines, P. W. Cyr and E. H. Sagent, Appl. Phys. Lett., 2004, 84, 4295.

8 L. Manna, E. C. Scher and A. P. Alivisatos, J. Am. Chem. Soc., 2000, 122, 12700

9 C. X. Shan, Z. Liu and S. K. Hark, Nanotechnology, 2005, 16, 3133.

10 L.-S. Li, J. Hu, W. Yang and A. P. Alivisatos, Nano Lett., 2001, 1, 349.

11 A. Singh, X. Li, V. Protasenko, G. Galantai, M. Kuno, H. Xing and D. Jena, Nano Lett., 2007, 7, 2999.

12 (a) J.-M. Zhu and H.-Y. Chen, Adv. Mater., 2003, 15, 156; (b) Y. Hu, J. Chen, W. Chen and J. Ning, Mater. Lett., 2004, 58, 2911; (c) L. Dloczik, R. Engelhardt, K. Ernst, S. Fiechter, I. Sieber and R. Konenkamp, Appl. Phys. Lett., 2001, 78, 3687; (d) Q. Peng, S. Xu, Z. Zhuang, X. Wang and Y. Li, Small, 2005, 1, 216; (e) B. Liu, T. Ren, J.-R. Zhang, H.-Y. Chen, J.-J. Zhu and C. Burda, Electrochem. Commun., 2007, 9, 551; (f) C. N. R. Rao, A. Govindarj, F. L. Deepak, N. A. Gunari and M. Nath, Appl. Phys. Lett., 2001, 78, 1853.

13 (a) C. N. R. Rao, F. L. Deepak, G. Gundiah and A. Govindaraj, Prog. Solid State Chem., 2003, 31, 5; (b) Y. Xia, P. Yang, Y. Sun, Y. Wu, B. Mayers, B. Gates, Y. Yin, F. Kim and H. Yan, $A d v$. Mater., 2003, 15, 353; (c) B. Mayers, B. Gates and Y. Xia, Int. J. Nanotechnol., 2004, 1, 86.

14 (a) Q. Zhang, C. S. Dandeneau, X. Zhou and G. Cao, Adv. Mater. 2009, 21, 1; (b) A. B. F. Martinson, J. W. Elam, J. T. Hupp and M. J. Pellin, Nano Lett., 2007, 7, 2183.

15 (a) J. Hu, T. W. Odom and C. M. Lieber, Acc. Chem. Res., 1999, 32, 435; (b) G. Wang, X. Yang, F. Qian, J. Z. Zhang and Y. Li, Nano Lett., 2010, 10, 1088; (c) C. M. Lieber, Solid State Commun., 1998, 107, 607.

16 I. Gur, N. A. Fromer, C.-P. Chen, A. G. Kanaras and A. P. Alivisatos, Nano Lett., 2007, 7, 409.
17 (a) M. Law, L. E. Green, J. C. Johnson, R. Saykally and P. Yang, Nat. Mater., 2005, 4, 455; (b) C. Y. Jiang, X. W. Sun, G. Q. Lo, D. L. Kwong and J. X. Wang, Appl. Phys. Lett., 2007, 90, 263501; (c) Z. R. R. Tian, J. A. Voigt, J. Liu, B. McKenzie and M. J. McDermott, J. Am. Chem. Soc., 2002, 124, 12954; (d) D. B. Kuang, A. W. Xu, Y. P. Fang, H. Q. Liu, C. Frommen and D. Fenske, Adv. Mater., 2003, 15, 1747; (e) H. Yuan, W. Ma, C. Chen, J. Zhao, J. Liu, H. Zhu and X. Gao, Chem. Mater., 2007, 19, 1592; $(f)$ H. L. Cao, X. F. Qian, C. Wang, X. D. Ma, J. Yin and Z. K. Zhu, J. Am. Chem. Soc., 2005, 127, 16024.

18 V. R. Shinde, H.-S. Shim, T. P. Gujar, H. J. Kim and W. B. Kim, $A d v$. Mater., 2008, 20, 1008 .

19 (a) H.-S. Shim, V. R. Shinde, J. W. Kim, T. P. Gujar, O.-S. Joo, H. J. Kim and W. B. Kim, Chem. Mater., 2009, 21, 1875; (b) S.-W. Ko, J. W. Kim, G. D. Moon, H.-S. Shim, W. B. Kim and U. Jeong, Langmuir, 2010, 26, 4377.

20 (a) Q. Peng, Y. Dong, Z. X. Deng and Y. Li, Inorg. Chem., 2002, 41, 5249; (b) H. Zhu, M. Sun and X. Yang, Colloids Surf., A, 2008, 320, 74.

21 A. B. Ellis, S. W. Kaiser and M. S. Wrighton, J. Am. Chem. Soc., $1976,98,6855$.

22 P. H. C. Camargo, Y.-H. Lee, U. Jeong, Z. Zou and Y. Xia, Langmuir, 2007, 23, 2985.

23 (a) J. E. Bowen Katari, V. L. Colvin and A. P. Alivisatos, J. Phys. Chem., 1994, 98, 4109; (b) J. F. Moulder, Handbook of X-Ray Photoelectron Spectroscopy, Physical Electronics, Ins, Minnesota, 1995.

24 (a) F. Zhang, Y. Shi, X. Sun, D. Zhao and G. D. Stucky, Chem. Mater., 2009, 21, 5237; (b) H. J. Fan, U. Gosele and M. Zacharias, Small, 2007, 3, 1660; (c) X. W. Lou, L. A. Archer and Z. Yang, Adv. Mater., 2008, 20, 3987; (d) A. D. Smigelskas and E. O. Kirkendall, Trans. Am. Inst. Min., Metall. Pet. Eng., 1947, 171, 130.

25 K. N. Tu and U. Gosele, Appl. Phys. Lett., 2005, 86, 093111.

26 Y. Yin, C. K. Erdonmez, A. Cabot, S. Hughes and A. P. Alivisatos, Adv. Funct. Mater., 2006, 16, 1389.

27 A. G. Kanaras, C. Sonnichsen, H. Liu and A. P. Alivisatos, Nano Lett., 2005, 5, 2164 